\section{Participação, produção de conhecimento e pesquisa avaliativa: a inserção de diferentes atores em uma investigação em saúde mental}

\author{
Participation, knowledge production, and evaluative \\ research: participation by different actors in a \\ mental health study
}

\author{
1 Universidade Federal de \\ São Paulo, Santos, Brasil. \\ 2 Faculdade de Ciências \\ Médicas, Universidade \\ Estadual de Campinas, \\ Campinas, Brasil. \\ Correspondência \\ J. P. Furtado \\ Universidade Federal de \\ São Paulo. \\ Av. Francisco Glicério 614 , \\ apto. 12, Santos, $S P$ \\ 11065-400, Brasil. \\ juarezpfurtado@hotmail.com
}

\begin{abstract}
This article reflects on the interrelations between participation, knowledge production, and public policy evaluation in light of issues from our own experience with evaluative research on a municipal network of Psychosocial Care Centers (CAPS) in Brazil. The article discusses the coordination of the complex process and the potentials and limits of partnerships for conducting qualitative evaluative studies in mental health with participation by different social actors. The authors conclude that qualitative evaluative research aligned with the perspective of including different points of view representing various segments is the best approach for understanding the numerous spin-offs from the implementation of services linked to the Brazilian psychiatric reform movement, given the inherent specificities of the mental health field.
\end{abstract}

Mental Health Services; Health Services Research; Knowledge
Juarez Pereira Furtado 1

Rosana Onocko Campos 2

\section{A importância da participação na produção de conhecimentos sobre políticas públicas}

Abordaremos aspectos ligados à inclusão e articulação de diferentes atores ocorridos no transcorrer da pesquisa avaliativa da rede de Centros de Atenção Psicossocial (CAPS) do Município de Campinas, São Paulo, Brasil. A coordenação dos processos, aproximação e articulação com os atores e realização dos trabalhos de campo serão abordados sob a ótica da "participação" na avaliação de programas e serviços. Participação - e aqui mais especificamente avaliação participativa - entendida como um processo realizado por meio do estabelecimento de parcerias entre avaliadores e pessoas afetadas e/ou envolvidas por um determinado programa ou serviço e que não são avaliadores senso estrito, como profissionais do serviço, usuários, familiares, gestores etc. 1,2 . Preliminarmente, faremos algumas reflexões sobre as relações entre políticas sociais e participação.

As políticas sociais representam, da parte do Estado, um esforço planejado de reduzir desigualdades sociais. Da parte dos grupos de interesse representam a conquista da autopromoção. Ambos os pontos de vista - do Estado e dos grupos de interesse - concordam no que concerne ao caráter redistributivo das políticas sociais. No entanto, podem apresentar divergência na medida em que o Estado procura (quando procura!) 
redistribuir renda, e os grupos de interesse podem buscar, além disto, a redistribuição de poder. Temos aí uma divergência de enfoque que não implica necessariamente antagonismo, mas em complementaridade, uma vez que constitui a essência da política social seu caráter redistributivo e autopromotor: redistribuição de renda e de poder ${ }^{3}$. Ou seja, política social é aquela que efetivamente promove a redistribuição de bens e poder, tendo como eixo de sustentação a noção do que mais recentemente se convencionou chamar de empoderamento 4 de sua clientela. Nesse sentido, a vertente política (relativa à participação e aos diferentes graus de co-gestão possíveis) deveria assumir a mesma importância das outras duas vertentes - sócio-econômica (ocupação e renda) e assistencial (voltada ao sustento de grupos que não podem fazê-lo) que em tese constituem as políticas sociais. Podemos, então, depreender que a participação é uma condição necessária a uma política social realmente comprometida com mudanças sociais, podendo ser o meio para que se previna a degradação da assistência em assistencialismo e/ou o domínio da vertente socioeconômica pela tecnocracia.

Devemos relativizar, no entanto, as potencialidades da participação, uma vez que a mesma tem inserção privilegiada nas chamadas condições subjetivas e históricas de mudança, o que pode não ocorrer quando se trata de condições objetivas ou estruturais, que necessitariam de outras intervenções para serem essencialmente alteradas. Nas palavras de Demo $^{3}$ (p. 6; grifo nosso, "a política social participativa busca resgatar a problemática das condições subjetivas, no sentido da importância da organização política, dentro de estruturas dadas, quer dizer, sem secundarizar a questão da base objetiva material".

Essas relações dialéticas marcadas, por um lado, entre determinismos de diversas ordens impostos pelas estruturas materiais objetivas e, por outro, pela capacidade dos sujeitos em resistirem ou desviarem desses constrangimentos, ainda que dentro das estruturas dadas (sejam serviços, programas etc.) vêm sendo trabalhadas por Campos 5,6 mais especificamente no âmbito das equipes de saúde.

A participação tem sido considerada fator constitutivo das políticas sociais e condição sine qua non para atingir o objetivo de autopromoção e empoderamento. Nessa perspectiva, nos aproximamos da idéia central que sustenta a presente discussão: se a participação popular é elemento vital e constituinte das políticas públicas - sobretudo se quisermos que estas superem seus riscos de degradação e manipulação e efetivamente cumpram sua missão de assistir e empoderar - podemos afirmar então que a participação da comunidade e de grupos de interesse na produção de conhecimentos em torno destas políticas públicas seria igualmente desejável.

Identificamos assim, convergência e necessária articulação entre participação popular, que deve influenciar a formulação, execução, fiscalização e avaliação de políticas públicas e serviços básicos na área social 7,8 e a participação de diferentes segmentos da comunidade na produção de conhecimentos sistemáticos sobre estas mesmas políticas ou serviços. A avaliação participativa de programas e serviços na área social, seria assim, tributária das relações entre participação popular e políticas públicas por um lado e pesquisa e ação, por outro.

Com relação a essa última, devemos considerar que as interações entre pesquisa e ação atendem por diversos nomes: pesquisa-ação, pesquisa ação-participativa, pesquisa baseada na comunidade, pesquisa colaborativa, dentre outros 9,10. Essas abordagens inserem profissionais, cidadãos, pacientes etc., ligados ao objeto em estudo que por suas formações, status social, experiências ou especialidades são normalmente colocados à margem da produção científica.

Se considerarmos que os processos avaliativos destinam-se a garantir transparência social, permitindo saber afinal o que se passa com aquilo que formulamos, a necessidade de plural participação do maior número de atores legitimamente implicados (na condição de promotores e beneficiários diretos ou indiretos) torna-se evidente. Além disso, há que se procurar minimizar eventuais prejuízos que tomadas de decisão advindas de processos avaliativos unilaterais possam trazer aos grupos de interesse ligados a um dado programa ou serviço 11 .

A inclusão de tais segmentos se justificaria pela potencialidade em tornar as investigações mais significativas e culturalmente apropriadas aos diferentes grupos de interesse - sobretudo quando se aborda problemas sociais que por sua natureza e complexidade exigem soluções coletivas 12. Poder, democracia e mudança social constituiriam o coração da pesquisa participativa, afirmou Towsend et al. 13. Teríamos nessa tríade as bases de sustentação do que consideramos como pesquisa avaliativa participativa de programas e serviços em saúde, educação e outras iniciativas no âmbito social, sobretudo quando consideramos o compromisso de pesquisas avaliativas com a tomada de decisão e mudança 14,15 .

No caso específico da avaliação de políticas públicas de saúde mental, no contexto da reforma psiquiátrica, a realização de pesquisas avaliativas de caráter participativo pode auxiliar sobremaneira a reflexão e a impressão de carac- 
terísticas locais às diretrizes gerais concebidas no plano federal pelo Sistema Único de Saúde 16,17.

\section{Participação: pragmatismo, ideologia ou postura epistemológica?}

Não pretendemos aqui inventariar as raízes teóricas e as práticas em torno dos binômios "pesquisa e ação”. Essas têm precursores e pesquisadores distantes no tempo, tanto no que se refere às várias formas de interação entre pesquisa e ação social 9,18,19,20 quanto à questão da participação e da negociação no campo da avaliação de programas e serviços $11,21,22$.

Para Weaver \& Cousins 23, haveria três razões ou objetivos ligados à opção pela avaliação participativa em relação às outras opções possíveis e que moveriam os pesquisadores, a saber: pragmática; política e ideológica; e epistemológica. Naturalmente, pode haver diferentes combinações desses interesses ou o predomínio e ênfase em algum deles. Os interesses de ordem pragmática estariam ligados às expectativas de efetiva utilização do conhecimento gerado na pesquisa avaliativa para a solução dos problemas. Membros da comunidade, trabalhadores e, sobretudo, detentores de poder de decisão seriam engajados de modo a garantir que aquilo que é percebido como problema seja realmente abordado e que a participação no processo aumente a permeabilidade e apropriação, por este coletivo, dos resultados da investigação.

A segunda justificativa, política e ideológica, baseia-se nas idéias de justiça social e democracia. Por meio do envolvimento no processo de avaliação (ou de pesquisas em geral) indivíduos pertencentes a grupos oprimidos e setores marginalizados teriam a oportunidade de se fazer ouvir e de influenciar o curso de um dado programa ou serviço, podendo também aumentar seu poder de compreender e agir (empoderamento). A terceira e última razão, epistemológica, deriva da aceitação de que a realidade é sempre construída e que somente por meio da consideração de variadas perspectivas é que se poderia aproximar melhor daquilo que se convenciona chamar de "fatos" 1,23.

O predomínio de uma das razões apontadas acima levaria a três tipos possíveis de avaliação participativa 23 , que foram retomadas e adaptadas recentemente por Ridde 1 . Teríamos assim avaliação participativa do tipo pragmática quando voltada essencialmente para a solução de problemas particulares ou para a realização de melhorias em um dado programa, sendo caracterizada por pequenos graus de disputa de poder e pelo envolvimento de grupos com algum poder de decisão em torno do problema abordado.
A avaliação participativa pluralista (stakeholder-based evaluation) seria especialmente utilizada quando o avaliador antevê a existência de importantes conflitos de valores entre diferentes grupos de interesse. Nesse caso, assegurando sempre o controle do processo, os avaliadores deverão garantir a compreensão e a consideração das diferentes perspectivas e concepções que sustentam determinados atores envolvidos com o programa ou serviço avaliado. As características do campo no qual desenvolvemos nossa pesquisa e a forma como vem sendo conduzida a enquadrariam nesse tipo de avaliação participativa, sempre considerando, no entanto, a inexistência de um tipo puro.

Finalmente, a avaliação participativa emancipadora teria como cerne o empoderamento, o desenvolvimento dos participantes não avaliadores, dotando-os de capacidade - tanto na forma quanto do conteúdo do estudo desenvolvido - e aumentando sua capacidade de intervenção na realidade cotidiana. Para Zúñiga \& Laperrière 24, a avaliação participativa emancipadora atinge seu objetivo primordial quando possibilita aos diversos segmentos envolvidos a tomada de consciência das posições sustentadas por si e pelos outros grupos e das ações daí decorrentes, trazendo à tona as idéias de conscientização tão caras a Paulo Freire.

\section{Constituindo a participação}

Em trabalho de revisão sobre estratégias participativas em pesquisa, Brose 12 afirma ser mais comum, entre os autores, a formulação de recomendações do que a discussão detalhada e rigorosa sobre o desenrolar de iniciativas desta natureza no interior de ambientes institucionais, acadêmicos e de grupos e comunidades, com toda a complexidade relacional e política ali envolvida. Em nosso caso, detalharemos e discutiremos alguns aspectos aparentemente corriqueiros mas que, na verdade, constituem-se elementos decisivos na condução de investigações como esta que estamos discutindo.

Na elaboração de nosso projeto, consideramos inicialmente dois importantes atores sociais que constituem a rede campineira de saúde mental: a secretaria municipal de saúde e uma organização não-governamental reconhecida nacionalmente. Razões de diversas ordens - que não caberia aqui detalhar - fazem com que a concepção e valores relativos aos modos de funcionamento dos CAPS, entre esses dois atores, sejam divergentes. Por isso, elegemos o espaço que congrega dirigentes de todos os CAPS que operam no município, chamado fórum de gerentes e composto pela coordenadora municipal de 
saúde mental e dirigentes dos CAPS do município - independente de sua vinculação a uma ou outra organização - como ponto de partida para a apresentação de nosso projeto de pesquisa, então recém-aprovado pelos financiadores (Fundo Setorial do Ministério da Saúde e Conselho Nacional de Desenvolvimento Científico e Tecnológico- $\mathrm{CNPq}$ ).

Nesse primeiro encontro, fizemos a apresentação detalhada da investigação e entregamos uma síntese impressa do projeto, endereçada aos membros das equipes. Pauta importante nessa reunião foi a discussão e aprovação da proposta de formação de um comitê - o Comitê Científico - a ser constituído por um representante de cada CAPS (definidos pelas respectivas equipes e gerentes) e pelos dois coordenadores da pesquisa (que são autores do presente artigo). Os integrantes do Comitê deveriam estabelecer elos e interlocuções entre o grupo de estudos Saúde Mentale Saúde Coletiva:Interfaces e as respectivas equipes nos aspectos operacionais e técnicos da investigação a ser feita, incluindo o desenvolvimento das ações de campo. Outra expectativa era a de que os membros do Comitê pudessem assimilar, de especial maneira, aspectos metodológicos e conceituais envolvidos no estudo. Um pequeno pro-labore foi previsto para os integrantes desse Comitê para ressarci-los pelos deslocamentos e tempo de participação nas reuniões.

Na primeira fase de campo, realizamos dez grupos focais que previam a participação de: 72 trabalhadores (12 de cada um dos 6 CAPS); dos sete integrantes do colegiado de saúde mental do município; dos seis gerentes dos respectivos CAPS que compõem a rede de saúde mental em estudo. Realizamos também um grupo focal com familiares e outro com usuários, respectivamente. Os trabalhadores participantes foram definidos pela própria equipe, que deveria garantir que metade dos mesmos fosse constituída por detentores de diploma universitário e todos filiados, no mínimo, há seis meses no serviço. Familiares e usuários também foram definidos pelas equipes, que deveria observar vinculação de seis meses ao serviço e capacidade de participação nos grupos propostos.

Diferentemente dos grupos com profissionais, aglutinados segundo o serviço em que trabalhavam, no caso de familiares e usuários convidamos dois representantes de cada um dos CAPS, agrupando pessoas ligadas a diferentes unidades. Totalizamos assim dez grupos focais realizados nos meses 4 e 5 do cronograma de pesquisa (o cronograma constante no projeto de pesquisa aprovado prevê 24 meses para a realização completa da mesma). Na segunda fase de campo, nos meses 9 e 10 do cronograma da pesquisa, refizemos os grupos com as mesmas clientelas. Totalizamos assim vinte grupos nas duas etapas de campo.

Remetemos à cooperação entre os condutores da pesquisa e o Comitê Científico a significativa participação dos convidados na grande maioria dos grupos focais, na medida em que os componentes do Comitê puderam interagir com seus pares, motivando-os para a participação nos grupos e esclarecendo aspectos operacionais, como local e data dos encontros, que foram sempre realizados em espaços exteriores aos respectivos serviços, porém no dia e hora em que habitualmente realizavam suas reuniões. Tivemos, em média, 11 participantes dentre 12 convidados nos seis grupos de trabalhadores. Nos grupos de gerentes e gestores participaram a totalidade dos convidados, configurando significativo número de participantes 25,26 . Nos grupos de familiares e usuários tivemos, no entanto, a participação média de seis pessoas por grupo, para um universo de 12 convidados.

Além dos grupos focais, os integrantes do Comitê foram de especial importância no acesso a dados quantitativos referentes aos respectivos serviços. Como as informações não estavam sistematizadas nos serviços, o conhecimento das fontes informais de informações pelos integrantes do Comitê foi decisivo. Além disso, tratava-se de pessoal interno ao serviço coletando informações sobre o mesmo, o que pôde reduzir eventuais resistências.

A segunda etapa de campo constituiu-se essencialmente da apresentação, a cada um dos grupos participantes da primeira fase, das narrativas elaboradas com base na transcrição dos primeiros grupos focais. Devemos salientar que a opção pela elaboração de narrativas baseando-se nos grupos focais parte da convicção de que trabalhadores, usuários e familiares são detentores privilegiados do conhecimento sobre as práticas, modalidades, desafios e entraves dos serviços em questão. Alinhavamos histórias a partir de "migalhas de histórias", construímos "histórias não (ainda) narradas" 27, utilizando o material transcrito dos grupos não para esmiuçá-lo, analisá-lo ou suspeitar dele, senão para contribuir com a vinda ao mundo de novos argumentos dos grupos citados. Quisemos assim dar voz a vozes da maneira mais ampla e concatenada possível - o que as narrativas nos parecem permitir de maneira especial. Apresentamos a seguir uma síntese de nosso percurso metodológico (Figura 1).

De maneira sintética, podemos afirmar que se constituíram espaços formais e propícios à participação de diferentes segmentos nos rumos da investigação: 

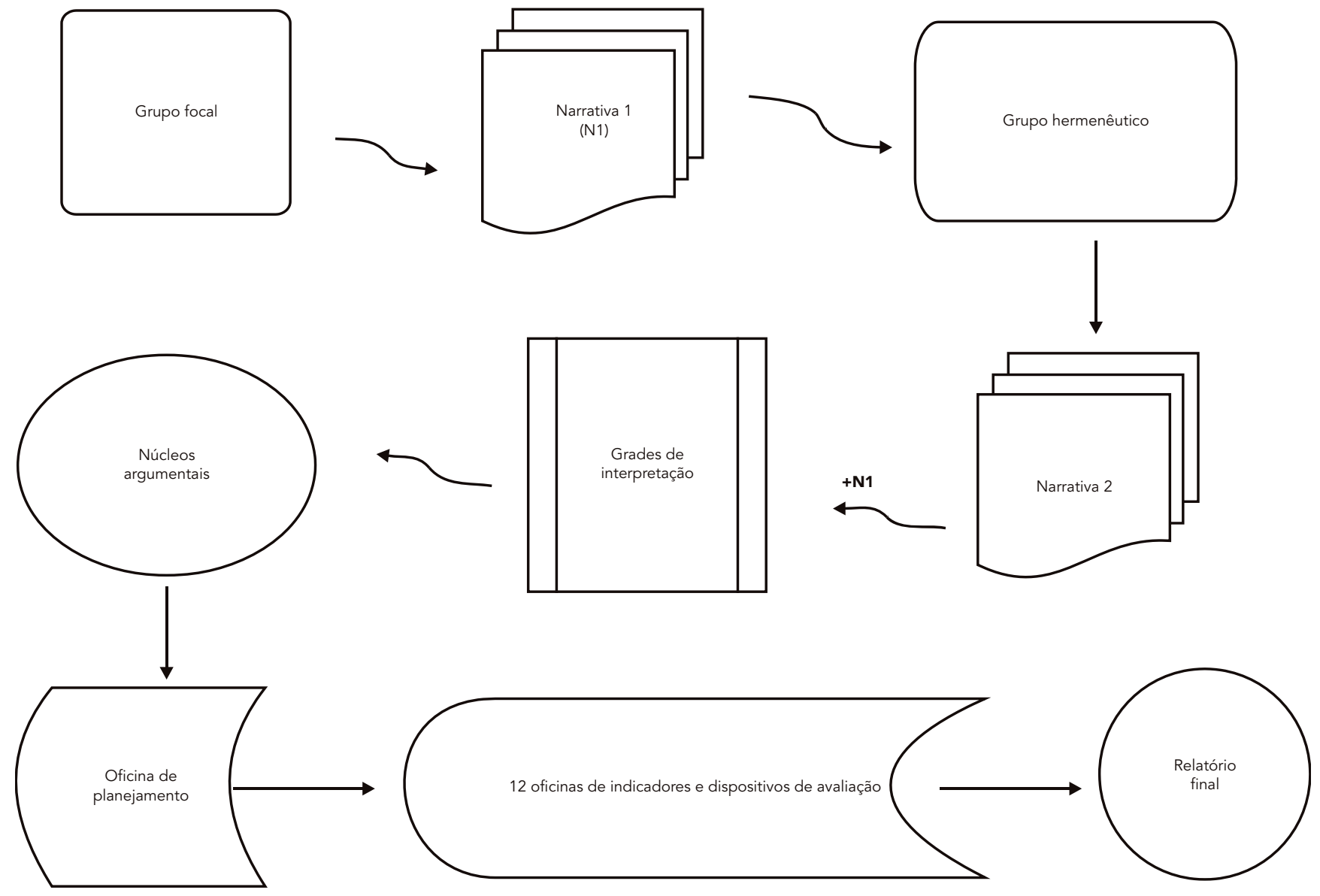

- As reuniões no fórum de gerentes de CAPS, no qual debateu-se diferentes aspectos da pesquisa por várias vezes;

- O I Seminário Internacional, realizado no mês 3 do cronograma, voltado para discutir aspectos metodológicos e formais da pesquisa, que contou com a presença de dezenas de profissionais da rede (um segundo seminário similar está previsto para proximamente, voltado para a apresentação e discussão dos resultados com diferentes grupos de interesse);

- O Comitê Científico;

- Os grupos focais e hermenêuticos que, além de gerarem informações de interesse estrito da pesquisa, constituíram-se em espaço para a formulação de questões e iniciativas a serem consideradas na investigação, como a inclusão de atores não previstos no projeto original;
- A oficina de planejamento, que agregou o fórum de gerentes e o Comitê Científico em torno dos resultados preliminares da pesquisa e no delineamento das oficinas de processamento dos resultados da pesquisa avaliativa;

- E finalmente as referidas oficinas de processamento dos resultados: cinco grupos de aproximadamente trinta componentes (entre usuários, trabalhadores e gestores) que em dois encontros cada extraíram conseqüências dos resultados da pesquisa relativos aos temas mais problemáticos identificados na mesma, pactuando decisões, indicadores e dispositivos.

Devemos ressaltar, na constituição e/ou participação nesses fóruns, o esforço de criar condições para pactuações entre atores diversificados e, em alguns casos, divergentes e que não necessariamente chegaram a consensos como proposto no 
círculo hermenêutico de Guba \& Lincoln 11. Além disso, o processo de participação foi gradativo. Partimos de um projeto elaborado exclusivamente pelos pesquisadores por conta de constrangimentos formais e de prazos - afinal, as agências financiadoras (salvo exceções) não prevêem financiamentos que cubram o prazo e despesas inerentes à ampliação de autorias de propostas, ainda que participativas.

Porém, paulatinamente o controle técnico e operacional antes centrado no grupo de pesquisa foi sendo discutido e compartilhado com os grupos de interesse, sendo as oficinas finais, de processamento dos resultados, um espaço por excelência não só para apropriação do conhecimento gerado, mas sobretudo para a construção coletiva de conseqüências de todo o percurso empreendido 28 .

\section{Limites e potencialidades da participação}

Baseando-se num roteiro (Tabela 1), discutiremos como a dimensão "participação" foi contemplada em nossos trabalhos e quais questões suscitou. Para Weaver \& Cousins 23 poderíamos interrogar as diferentes práticas concretas de avaliação que se pretendem participativas com base em cinco dimensões inerentes a processos participativos. Questões como: quem controla o estudo; quais diversidades foram consideradas; que tipo de relação se estabelece (ou se impõe) entre os participantes; qual a flexibilidade da gestão da pesquisa no desenrolar das ações; e em que grau se dá o envolvimento dos participantes, tornam-se fundamentais para se delimitar o tipo de participação efetivamente realizada (no caso de pesquisas já concluídas) ou como se pretende venha a ser a participação (no caso de projetos).

Abaixo, reproduzimos a tabela contendo as cinco dimensões do processo de avaliação participativa (Tabela 1) adaptado por Ridde 1 valendo-se das idéias originalmente formuladas por Weaver \& Cousins ${ }^{23}$. Utilizamos essa tabela como um roteiro para orientar nossas reflexões baseadas na pesquisa avaliativa que concluímos.

\section{Decisões técnicas essenciais}

Estas já haviam sido tomadas por ocasião da submissão de nosso projeto à agência financiadora para a sua aprovação. Ou seja, as ações do Comitê Científico ficaram inicialmente restritas a aspectos operacionais da pesquisa em sua primeira etapa, caracterizada pela coleta de dados por meio dos grupos focais e dos questionários aplicados. Houve poucas discussões de caráter metodológico ou epistemológico do estudo e menos ainda das repercussões políticas da iniciativa nos primeiros contatos e encontros.

Tanto no fórum de gerentes quanto no Comitê Científico as diferenças entre os vários serviços e uma certa desconfiança destes em relação aos propósitos da universidade eram evidentes. Sabemos que o significante "avaliação" comporta muitos sentidos. Somos avaliados desde que nascemos e via de regra as experiências não são muito boas, fazendo com que o fato de nomear uma pesquisa de "avaliativa" suscite diversos temores, cuja superação junto aos grupos envolvidos pode tornar-se a primeira tarefa de um avaliador 29. Questões sobre garantias éticas da pesquisa e refratariedade a mudanças ou a ações que não estivessem claramente inseridas no contrato inicial - como a inclusão de novos subprojetos da pesquisa - eram freqüentes por parte dos integrantes do Comitê.

A sucessão de encontros centrados em tarefas e o efeito simbólico do pagamento de um pequeno pro labore são fatores cuja soma parece ter contribuído para instaurar um clima de trabalho eficaz no Comitê Científico. Acrescentaríamos aí a gradativa percepção de controle parcial, por parte das equipes ali representadas, no processo: afinal os integrantes dos grupos focais seriam definidos pelos coletivos de cada serviço e o questionário seria adaptado com o auxílio deles e aplicado por eles próprios, configurando evidente poder de interferir nas chamadas decisões técnicas.

À proporção que as equipes se viam efetivamente detentoras do poder de revelar (em diferentes intensidades) ou não dados e informações, passamos a verificar mais confiança para interferir nos rumos do processo. No entanto, tememos a instauração do que Zúñiga 30 identificou como estratégia ambivalente em grupos comunitários avaliadores: uma ação plenamente consciente de estar duplamente enraizado - na comunidade com a qual se identificam e nas relações que estabelecem com os gestores ou financiadores - levando à elaboração de um discurso interno de cumplicidade solidária e outro destinado a atender expectativas.

\section{Diversidade dos grupos participantes}

Considerando as limitações de tempo e financiamento, foram considerados trabalhadores, gestores, usuários e familiares, além da inclusão de alguns outros atores como detalharemos à frente. Ainda que qualitativamente tenhamos contemplado um leque razoável de grupos de interesse, caberia indagar sobre o menor número de grupos focais com usuários e familiares. Diferentemente dos profissionais, que foram ouvidos 
Escala de valores das cinco dimensões do processo de avaliação participativa.

\begin{tabular}{ll}
\hline Dimensão & Questão \\
\hline $\begin{array}{l}\text { 1. Controle de decisões técnicas } \\
\text { 2. Grupos de interesse participantes }\end{array}$ & Como se compartilha decisões técnicas ligadas ao processo avaliativo? \\
3. Relação de poder entre os grupos de interesse & Qual é a diversidade dos grupos de interesse entre os participantes? \\
4. Plasticidade do processo de gestão da pesquisa & Como se deu a participação dos diferentes grupos de interesse? \\
5. Nível de participação & Como se caracteriza a permeabilidade do processo avaliativo ao meio na qual transcorreu?
\end{tabular}

Adaptado de Ridde ${ }^{1}$ (p. 5).

em conjunto segundo sua vinculação a cada um dos seis serviços, os usuários e familiares foram respectivamente reunidos em grupos que aglutinavam pessoas ligadas à totalidade dos serviços estudados. Como conseqüência, tivemos menor número de grupos e, potencialmente, menor chance de extrair diferentes perspectivas desses dois atores sociais.

Além disso, ao contrário de todos os outros grupos, o de familiares e usuários registraram menor número de presenças se comparados aos demais. Caberia aqui indagar se o fato de o Comitê Científico ser constituído apenas por técnicos universitários não teria privilegiado a comunicação entre pares, dificultando a interação com os outros segmentos, como usuários e familiares, determinando inclusive menor participação destes nos grupos focais. Sabemos que a questão da participação dos usuários é central nas novas políticas de saúde mental, e que sua efetiva inserção nos movimentos políticos e nas investigações ainda encontra barreiras e dificuldades intrínsecas e extrínsecas para a sua realização 31,32 . Tais dificuldades parecem estar espelhadas na restrita participação desses dois segmentos nesta pesquisa. Resta saber, no entanto, que dispositivos poderiam ser utilizados em estudos similares e posteriores para atenuar ou mesmo superar a restrita participação desses dois segmentos (familiares e usuários).

Outra questão ligada à diversidade dos grupos relaciona-se aos trabalhadores das unidades básicas e auxiliares de enfermagem. Inicialmente não previstos como grupos de interesse específico, sua importância foi considerada nos grupos focais fazendo com que fossem incorporados ao campo e suas perspectivas incluídas por meio de entrevistas semi-estruturadas 28 ou de novos grupos focais respectivamente.

\section{Relação de poder entre participantes}

Puderam ser detectadas nos grupos focais dos trabalhadores dos CAPS. Não só as diferenças, mas também as desigualdades sociais dos três extratos das equipes de saúde - médicos, outros profissionais universitários e técnicos de enfermagem - se refletiram na dinâmica dos grupos. Ficou evidente o predomínio das opiniões de médicos e outros profissionais universitários em detrimento dos técnicos de enfermagem, não só pelo uso da palavra por mais tempo como também pelo reconhecimento que estas geravam.

Levando-se em conta a importância de ampla e qualificada participação e, sobretudo, de que esta seja a mais profunda possível, caberia reflexão sobre a pertinência de agrupar categorias homogêneas, de modo a extrair pontos de vista com mais detalhamentos e menos constrangimentos, como fizemos no caso específico dos técnicos de enfermagem de um dos CAPS, que puderam ser ouvidos por meio de grupo focal exclusivo.

Carlini-Cotrim 26, dentre outros, recomendam que grupos focais idealmente não sejam feitos com pessoas do mesmo círculo de amizades ou trabalho, de modo a evitar que a livre expressão de idéias no grupo seja prejudicada pelo temor do impacto que estas opiniões terão posteriormente.

Ao optarmos pela realização de grupos focais compostos integralmente por profissionais de um mesmo serviço, inevitavelmente transpusemos para o interior dos grupos as relações de poder já estabelecidas entre os participantes - o que em si não deixa de ser um dado importante a ser observado no transcorrer dos encontros.

Porém, nossa opção baseou-se no privilégio de outro importante aspecto a ser também considerado na condução de grupos focais: a homogeneidade dos participantes em relação às características que interfiram fortemente na percepção do assunto em foco, que no caso seria melhor 
obtida ouvindo-se separadamente trabalhadores pertencentes a cada um dos serviços. As diferenças marcantes (e em alguns casos verdadeira cisão) entre os serviços analisados no que tange a algumas concepções e práticas, evidenciadas ao longo da pesquisa, acabaram por confirmar o acerto em privilegiarmos essa opção.

\section{Plasticidade do processo de gestão}

Esta pesquisa decorre originalmente do fato de o estudo ser qualitativo e, portanto, aberto ao contexto e ao fatores que emergem do processo, como aponta a inserção de grupos de interesse não previstos inicialmente, constituídos por auxiliares de enfermagem e coordenadores de unidades básicas.

Especial flexibilidade vem sendo demonstrada na condução das oficinas para definição de indicadores e dispositivos (Figura 1). Mais de uma centena de pessoas, dentre as quais usuários, familiares, trabalhadores dos CAPS, trabalhadores de outros serviços, coordenadores e gestores, tomaram contato com os resultados da pesquisa e definiram - dentre as principais questões apontadas pela avaliação - aquelas que deveriam contar com alguma forma de acompanhamento (indicadores ou dispositivos).

Nessas oficinas, aumentou-se quantitativa e qualitativamente a participação de usuários e familiares, além de trabalhadores. Centenas de pessoas, representando diferentes perspectivas e instituições pactuaram (em alguns casos discutiram sem chegar a consensos) ações com base no resultado da avaliação empreendida. Um tal nível de participação só seria possível havendo habilidade, por parte dos pesquisadores, em dar contornos ao mesmo tempo em que abriam espaços para o surgimento e consolidação de imponderáveis e imprevisíveis sugestões e articulações em torno da problemática coletivamente abordada. Note-se que nessa fase superamos a simples "identificação do ponto de vista dos usuários”, avançando em direção à efetiva inserção dos mesmos em ações mais complexas e propositivas.

Somente considerando essa complexidade faremos face a algumas armadilhas inerentes aos processos inclusivos. Ou seja, somente pela via da gestão flexível, aberta inclusive à inserção de outros atores em sua própria condução, poderemos evitar o controle criticado por Zúñiga \& Laperrière 24 (p. 136): “desde as comunidades cristãs até as realidades aparentemente dessacralizadas da atualidade, o chamado à participação sempre esteve justificado em termos de humanização da sociedade, tanto no político quanto no religioso, e o próprio processo de participação espelha re- gras práticas enraizadas em contextos específicos, sempre refletindo as relações de controle daqueles que propuseram ou impuseram uma maior participação".

\section{Nível de participação}

A profundidade da participação de não-avaliadores no processo, de certa forma foi contemplada nas discussões dos outros tópicos, visto constituir-se em pano de fundo de todos eles. No entanto, valeria ressaltar as idéias de Passos et al. 33, segundo as quais o nível de participação se deva dar "entre" e não somente "intra". Ou seja, a simples horizontalização dos processos avaliativos se por um lado antagonizam a verticalidade predominante, por outro corre-se o risco de neutralizar diferenças e fomentar o corporativismo em um dado programa ou serviço. Dessa forma, uma terceira via se constituiria pela transversalização, com o aumento do grau de comunicação intra e intergrupos, gerando uma tensão produtiva 33, tal qual tentamos fazer no percurso desta investigação, colocando não só equipes em contato consigo mesmas, mas também diferentes atores e serviços em interlocução.

\section{Conclusão}

A transposição dos princípios da reforma psiquiátrica para a prática traz novos desafios 17 . A saúde mental é um campo que tem na subjetividade e nas relações intersubjetivas componente fundamental de seu objeto e de seu modus operandi, tornando mais complexa a tarefa de avaliar programas e serviços desta natureza com base em instrumentos consagrados em outros contextos, o que levou a própria Organização Mundial da Saúde (OMS) a recomendar o desenvolvimento de indicadores novos e específicos para esta área 34 .

Além disso, conceitos como cidadania, autonomia e clínica dos novos equipamentos são decisivos nas novas iniciativas e de difícil aproximação e objetivação. Ao mesmo tempo, indicam que as novas respostas sociais ao sofrimento psíquico encontram-se nos meandros das práticas e dificilmente seriam captadas pela identificação da cobertura, número de consultas realizadas e congêneres. A mudança sentida na vida, a diferença produzida no cotidiano de todos os envolvidos (tanto no plano individual quanto dos diferentes coletivos) são ao mesmo tempo nuançadas e essenciais para a verdadeira análise e compreensão dos serviços em questão 35 . Nesse sentido, identificamos na convergência da pesquisa avaliativa qualitativa e na inclusão 
participativa de grupos de interesse no processo uma alternativa que permite contemplar mais apropriadamente o objeto em análise, podendo inclusive contribuir para a redução da especial refratariedade existente na saúde mental aos processos avaliativos 16 .

No entanto, como vimos no tópico anterior, faz-se necessária uma gestão realmente atenta e flexível do processo de investigação dessa na- tureza, de modo a garantir a inclusão da diversidade e verdadeira troca a despeito das diferenças de poder entre os atores envolvidos, além do que as agências financiadoras deveriam incluir nos prazos e financiamentos de projetos espaço para a efetiva inserção de grupos de interesse na própria elaboração da proposta, garantindo a participação em todas as etapas constituintes do estudo.

\section{Resumo}

No presente texto apresentamos considerações sobre pesquisa avaliativa qualitativa e participativa com base em investigação desta natureza realizada junto a uma rede municipal de Centros de Atenção Psicossocial (CAPS) ligados ao Sistema Único de Saúde (SUS). A coordenação do complexo processo, bem como as potencialidades e limites do estabelecimento de parcerias para a realização de trabalhos de investigação avaliativa qualitativa em saúde mental, com a inclusão de diferentes atores sociais, são aqui discutidas. Concluímos que a pesquisa avaliativa qualitativa aliada à perspectiva de inclusão de distintos pontos de vista dos vários segmentos envolvidos é a que melhor se adequa à compreensão dos muitos desdobramentos oriundos da implementação de serviços ligados ao movimento de reforma psiquiátrica brasileira, dado as especificidades inerentes ao campo da saúde mental.

Serviços de Saúde Mental; Pesquisa sobre Serviços e Saúde; Conhecimento

\section{Colaboradores}

Ambos os autores participaram igualmente de todas as etapas de elaboração do artigo.

\section{Agradecimentos}

Pesquisa financiada pelo Conselho Nacional de Desenvolvimento Científico e Tecnológico (CNPq - Edital MCT-CNPq/MS-SCTIE-DECIT/CT-Saúde no. 07/2005). 


\section{Referências}

1. Ridde V. Suggestion d'ameliorations d'un cadre conceptual de l'évaluation participative. La Revue Cannadienne d'Évaluation de Programme 2006; 21:1-24.

2. Stufflebeam D. Evaluation models. New Directions for Evaluations 2001; 89:7-98.

3. Demo P. Participação é conquista. São Paulo: Cortez Editora; 1999.

4. Vasconcelos EM. O poder que brota da dor e da opressão: empowerment, sua história, teorias e estratégias. São Paulo: Editora Paulus; 2003.

5. Campos GWS. Saúde Paidéia. São Paulo: Editora Hucitec; 2003

6. Campos GWS. Um método para análise e co-gestão de coletivos. São Paulo: Editora Hucitec; 2000.

7. Serapioni M, Romaní O. Potencialidades e desafios da participação em instâncias colegiadas dos sistemas de saúde: os casos de Itália, Inglaterra e Brasil. Cad Saúde Pública 2006; 22:2411-21.

8. Valla VV. Sobre participação popular: uma questão de perspectiva. Cad Saúde Pública 1998; 14 Suppl 2:S7-18.

9. Brandão C, Streck DR. Pesquisa participante. Aparecida: Editora Idéias \& Letras; 2006.

10. Dolbec A. La recherche-action. In: Gauthier B, organizador. Recherche sociale: de la problématique à la collecte des données. Quebec: Presses de l'Université du Québec; 2003. p. 505-40.

11. Guba EG, Lincoln YS. Fourth generation evaluation. Newbury Park: Sage Publications; 1989

12. Brose M. Metodologia participativa. Porto Alegre: Tomo Editorial; 2005.

13. Townsend M, Birch DE, Langley J, Langille L. Participatory research in a mental health clubhouse. Occupacional Therapy Journal of Research 2000; 20:18-44.

14. Worthen BR, Sanders JR, Fitzpatrick JL. Avaliação de programas: concepções e práticas. São Paulo: Edusp/Editora Gente; 2004.

15. Patton MQ. Utilization-focused evaluation. Beverly Hills: Sage Publications; 1997.

16. Onocko-Campos R, Furtado JP. Entre a saúde coletiva e a saúde mental: um instrumental metodológico para a avaliação da rede de Centros de Atenção Psicossocial (CAPS) do Sistema Único de Saúde. Cad Saúde Pública 2006; 22:1053-62.

17. Furtado JP, Onocko-Campos R. A transposição das políticas de saúde mental no Brasil para a prática nos novos serviços. Rev Latinoam Psicopatol Fundam 2005; 8:109-22.

18. Freire P. Pedagogia do oprimido. Rio de Janeiro: Editora Paz e Terra; 2005.

19. Thiollent M. Metodologia da pesquisa-ação. São Paulo: Cortez Editora; 2004

20. Brandão CR. Pesquisa participante. São Paulo: Editora Brasiliense; 1988.

21. Alkin MC. Evaluation roots: tracing theorists' views and influences. Thousand Oaks: Sage Publications; 2004.
22. Fetterman DM. Branching out or standing on a limb: looking to our roots for insight. In: Alkin MC, editor. Evaluation roots: tracing theorists' views and influences. Thousand Oaks: Sage Publications; 2004. p. 88-121.

23. Weaver L, Cousins JB. Unpacking the participatory process. Journal of Multidisciplinariy Evaluation 2004; 1:19-40.

24. Zúñiga RB, Laperrière H. Avaliação comunitária: conflitos verticais e ambigüidades metodológicas. In: Bosi MLM, Mercado F, organizadores. Avaliação qualitativa de programas de saúde: enfoques emergentes. Petrópolis: Editora Vozes; 2006. p. 118-44.

25. Wiggins GS. The analysis of focus groups in published research articles. Canadian Journal of Program Evaluation 2004; 19:143-64.

26. Carlini-Cotrim B. Potencialidades da técnica qualitativa grupo focal em investigações sobre abuso de substâncias. Rev Saúde Pública 1996; 30:285-93.

27. Ricoeur P. Tempo e narrativa. Tomo I. Campinas: Editora Papirus; 1997.

28. Onocko-Campos R, Furtado JP, Passos E, Benevides R, organizadores. Avaliação em saúde mental: participação, intervenção e produção de narratividade. São Paulo: Editora Hucitec; in press.

29. Furtado JP. Avaliação de programas e serviços. In: Campos GW, Minayo MCS, Akerman M, DrumondM, Carvalho UM, organizadores. Tratado de saúde coletiva. São Paulo: Editora Hucitec/Rio de Janeiro: Editora Fiocruz; 2006. p. 715-39.

30. Zúñiga R. La gestion amphibie. Revue Internationale d'Action Communautaire 1988; 19:157-68.

31. Soalheiro NI. Da experiência subjetiva à prática política: a visão do usuário sobre si, sua condição, seus direitos [Tese de Doutorado]. Rio de Janeiro: Escola Nacional de Saúde Pública, Fundação Oswaldo Cruz; 2003.

32. Nelson G, Ochocka J, Griffin K, Lord J. Nothing about me, without me: participatory action research with self-help/mutual aid organizations for psychiatric consumer/survivors. Am J Community Psychol 1998; 26:881-912.

33. Passos E, Benevides R, Souza TP, Gonçalves LLB, Tallemberg C, Carvalho HF, et al. A dimensão instituinte da avaliação. In: Onocko-Campos R, Furtado JP, Passos E, Benevides R, organizadores. Avaliação em saúde mental: participação, intervenção e produção de narratividade. São Paulo: Editora Hucitec; in press.

34. Organização Mundial da Saúde. Relatório sobre a saúde no mundo 2001. Saúde mental: nova concepção, nova esperança. Brasília: Organização Mundial da Saúde; 2001.

35. Barreto J. O umbigo da reforma psiquiátrica: cidadania e avaliação de qualidade em saúde mental. Juiz de Fora: Editora da Universidade Federal de Juiz de Fora; 2005.

Recebido em 01/Nov/2007

Versão final reapresentada em 27/Mar/2008

Aprovado em 08/Abr/2008 